\title{
Experiments on Reinforced Brick Masonry Vaulted Light Roofs
}

\author{
by F. López-Almansa, P. Roca, V. Sarrablo, X. Cahís, and J. M. Canet
}

\begin{abstract}
This paper describes structural tests of thin vaults made of reinforced brick masonry. The experiments consist of concentrated loading tests of 14 full-scale laboratory vaults. These vaults are designed to include common situations such as short- to midspan length, low-mid-high rise, rigid-flexible-sliding supports, instantaneous-sustained loading, low-high strength mortar, point-line loading, central-eccentric loading, point-line supports, hinged-clamped supports, symmetric-asymmetric shape, double layer versus single layer reinforcement, and uniaxial-biaxial bending, among others. The tests mainly aim to obtain the collapse loads and to characterize the pre-and post-peak response. The results show satisfactory structural performance, both in terms of ductility and strength. Moreover, it is possible to predict the structural response with numerical models developed specifically for this purpose. Flat specimens were also tested to determine the punching shear strength of the vaults. This work is part of a larger research project aimed at promoting innovative semi-prefabrication techniques for reinforced brick masonry vaulted light roofs.
\end{abstract}

Keywords: brick shells; light roofs; loading tests; reinforced brick masonry; vaulted roofs.

\section{INTRODUCTION}

Historical and traditional construction has made use of brick masonry in arches, shells, domes, and vaults, leading to slender, light, and ingenious solutions, whose strength is mostly guaranteed by the curved shape, as in the Spanish architect Rafael Guastavino's ${ }^{1}$ works. The Uruguayan engineer Eladio Dieste ${ }^{2,3}$ built a number of reinforced brick masonry vaults and double-curvature shells spanning up to $50 \mathrm{~m}(164 \mathrm{ft})$ with only a $12 \mathrm{~cm}$ (4.72 in.) thickness. Nowadays, such clever technologies are not widely used in spite of their numerous architectural advantages mainly because they are skilled-work-force consuming and there is a certain lack of structural design criteria; this lacks stems from the absence of enough experimental background and of both accurate numerical and efficient models to characterize the structural behavior of these vaults.

This paper describes part of a research project ${ }^{4}$ whose objective is to foster the use of reinforced brick masonry shells for vaulted light roofs spanning up to approximately $12 \mathrm{~m}$ (39.34 ft). The strategy consists of overcoming the aforementioned limitations by proposing semi-prefabrication and construction technologies, providing design criteria (after the proposal of numerical models to analyze the structural behavior), and performing structural testing. This paper focuses on the structural tests. The main objectives of these experiments were: 1) to validate the proposed semiprefabrication and construction technologies; 2) to investigate the structural performance of the vaults; and 3) to calibrate the numerical models developed. Only the second and third issues are dealt with in this paper. The tests were designed according to these objectives while accounting for time, budget, and space constraints. Two types of experiments were carried out: punching shear tests of small flat specimens and, mainly, loading tests on full-scale experimental vaults.

\section{RESEARCH SIGNIFICANCE}

Light reinforced brick masonry vaults constitute a convenient roofing technology. Their structural performance, however, is still difficult to characterize because of their intrinsic complexity, the lack of enough experimental evidence, and the unavailability of accurate numerical models. This paper presents a testing campaign aimed at reporting on the structural behavior of short- to midspan length vaults and at calibrating numerical models also derived by the authors. It is expected that this research will contribute to foster the use of light reinforced brick masonry vaults thanks to the satisfactory behavior shown by the experimental vaults and to the capacity shown by the numerical methods used to accurately predict their response.

\section{PROPOSED VAULTS}

The vaults are mainly intended to cover rectangular spaces, as shown in Fig. 1, depicting a rectangular space split in parallel strips. Each strip is composed of one or several semi-prefabricated sheets; for instance, in Fig. 1, each strip is composed of two sheets.

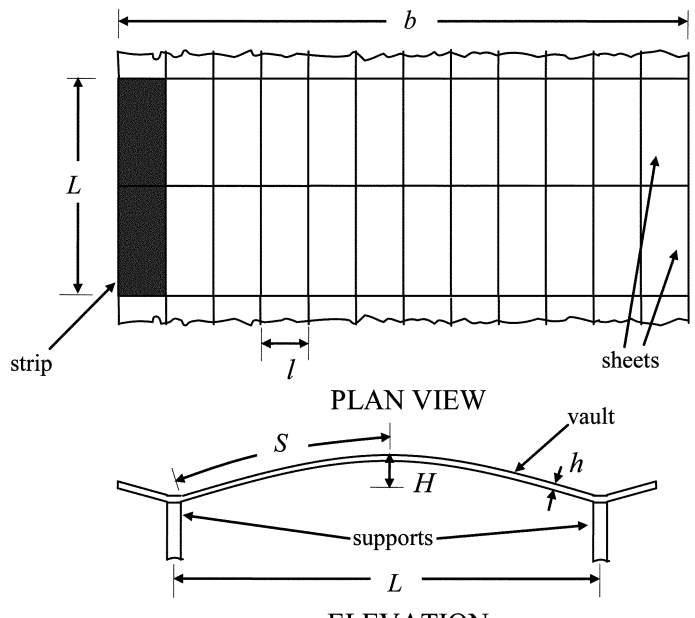

Fig. 1-Vaulted roof.

ACI Structural Journal, V. 107, No. 3, May-June 2010

MS No. S-2009-122.R4 received August 4, 2009, and reviewed under Institute publication policies. Copyright (C) 2010, American Concrete Institute. All rights reserved, including the making of copies unless permission is obtained from the copyright proprietors. Pertinent discussion including author's closure, if any, will be published in the March-April 2011 ACI Structural Journal if the discussion is received by November 1,2010. 
F. López-Almansa is a Professor in the Architecture Structures Department at the Technical University of Catalonia, Barcelona, Spain. He received his BS in civil engineering from the University of Valencia, Valencia, Spain, in 1976 and his PhD from the Polytechnic University of Catalonia, Catalonia, Spain, in 1988. His research interests include dynamics of structures, earthquake engineering, passive control of building structures, and experimental and numerical analysis of masonry and concrete structures.

P. Roca is a Professor in the Construction Engineering Department at the Technical University of Catalonia, Barcelona, Spain. He received his BS and PhD in civil engineering from the Technical University of Catalonia in 1985 and 1988, respectively. His research interests include historical constructions and experimental and numerical analysis of masonry and reinforced concrete structures.

V. Sarrablo is a Professor in the Architecture Construction Department at the International University of Catalonia. He received his $B S$ and $P h D$ in architecture from the Technical University of Catalonia in 1991 and 2002, respectively. His research interests include reinforced masonry structures and inflatable structures.

X. Cahís is a Professor in the Mechanical and Construction Engineering Department at the University of Girona, Spain. He received his $B S$ and PhD in mechanical engineering from the Technical University of Catalonia in 1990 and 2000, respectively. His research interests include earthquake engineering, energy dissipators, experimental analysis, and concrete structures.

J. M. Canet is a Professor in the Strength of Materials and Engineering Structures Department at the Technical University of Catalonia. He received his BS in civil nclude finite element analysis, dynamics of structures, and earthquake engineering.

The main geometrical parameters of the vaults are denoted as follows (refer to Fig. 1). The variable $L$ is the span length; $n_{L}$ is the number of parallel vaults (only a vault is shown in Fig. 1); $l$ is the width of each strip; $n_{i}$ is the number of strips per valt $\left(n_{l}=12\right.$ in Fig. 1$) ; b$ is $t$
$S$ is the arc-length of each sheet;
perstrip $\left(n_{S}=2\right.$ in Fig. 1$) ; H$ is the

is the vault thickness. Table arameters; "tested range" ered in the experiments
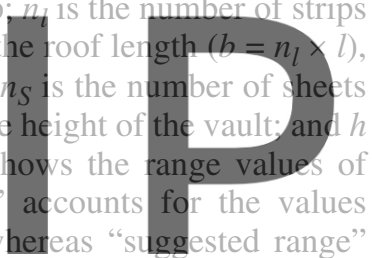

refers to the recommended values for real applications

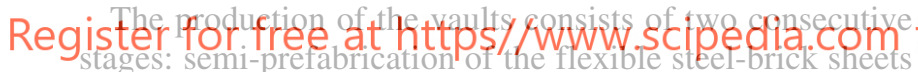

and on-site construction. Figure 2 displays a front and a side image of a completed sheet corresponding to the first stage.
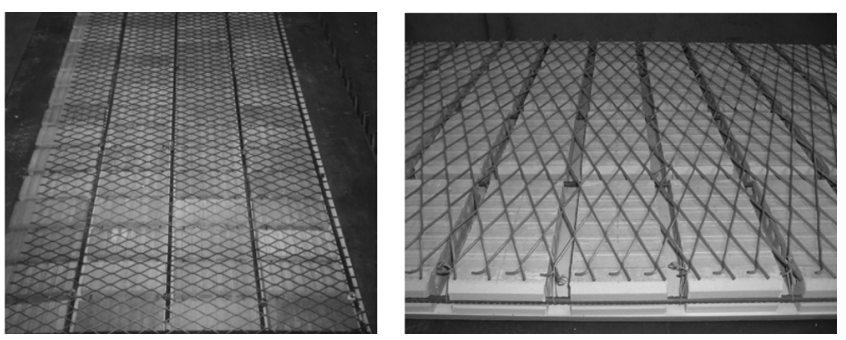

Fig. 2-Semi-prefabricated steel-brick sheets.
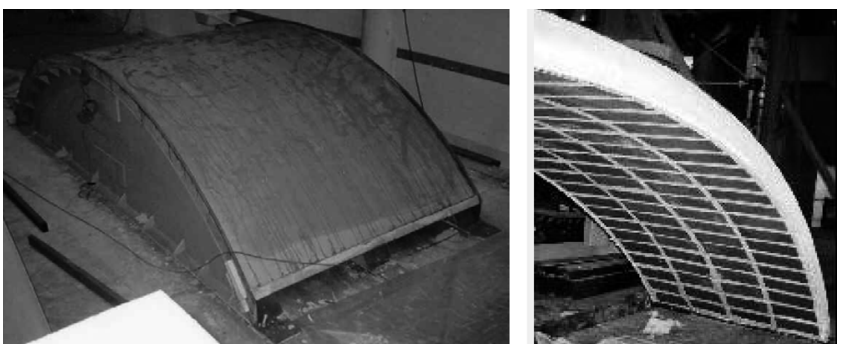

Fig. 3-Completed reinforced brick masonry vaults.
The right image of Fig. 2 shows that the semi-prefabricated sheets consist of an array of four rows of specially designed bricks housing five longitudinal steel reinforcement bars. Three bars lie along the three joints between the four rows whereas the other two bars are slotted in grooves of the bricks at both sides of the sheets, as shown by the right image in Fig. 2. The sheets are topped with an expanded metal layer. The aforementioned reinforcing bars are tied to such layer by wires; in this way, the sheets form monolithic flexible assemblies whose longitudinal axial and bending stiffness is only contributed by the steel reinforcement bars. These sheets are delivered flat to the construction site and are moved to their final position on vault-shaped light formworks. Then, the remaining reinforcement is placed and consists of lower transversal steel bars and an upper welded steel mesh resting on the expanded metal sheet. Hence, top and bottom bidirectional reinforcement exists. The construction is completed by pouring or spraying mortar or concrete to fill the joints and to form the topping layer. Figure 3 displays a pair of views of the extrados and the intrados of a completed vault and Fig. 4 shows a drawing of a cross section of a vault $1 \mathrm{~m}$ $(3.279 \mathrm{ft})$ wide.

\section{STRUCTURAL TESTS OF FULL-SCALE VAULTS Description}

The experiments involved static loading tests until failure on a set of vaults. Additionally, modal vibration analyses were performed. The vaults were shaped as catenary curves. To include as much realistic and relevant situations as

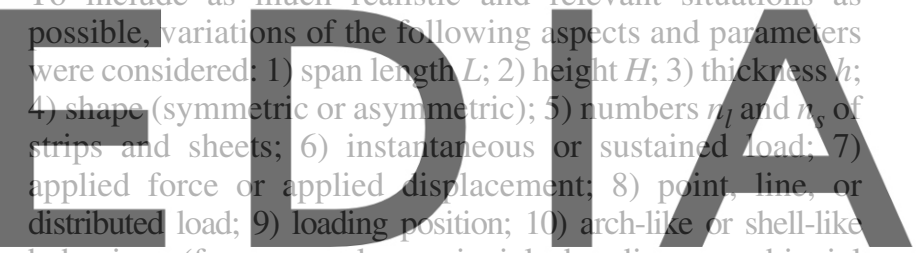
behavior (for example, uniaxial bending or biaxial bending); 11) hinged or clamped ends; 12) reinforcement

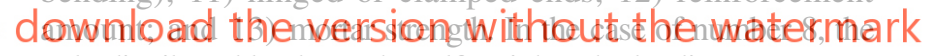
only distributed load was the self weight. The loading cases were chosen to represent the most common situations for light roofs.

Table 2 shows the main characteristics of the tested vaults.

The second column of Table 2 describes the main geometrical features of the vaults. All of the shapes were catenary symmetric. The third column describes the intended type of connection among the vaults and the supporting members. The fifth column contains the nominal values of the steel yielding points; tension tests showed that the actual values were significantly higher (that is, for steel with a nominal yielding point of $500 \mathrm{MPa}$ [72.5 ksi], the measured value ranged among 550 and $600 \mathrm{MPa}[79.75$ and $87 \mathrm{ksi}])$. The seventh column contains the mortar strength determined according to EN 1015-11. ${ }^{5}$ The brick compressive or tensile strength is not considered relevant as the observed failure

\section{Table 1-Range of geometrical parameters}

\begin{tabular}{c|c|c|c|c|c|c|c}
\hline $\begin{array}{c}\text { Geometrical } \\
\text { parameter }\end{array}$ & $L, \mathrm{~m}$ & $l, \mathrm{~m}$ & $S, \mathrm{~m}$ & $H, \mathrm{~m}$ & $h, \mathrm{~mm}$ & $n_{\mathrm{l}}$ & $n_{S}$ \\
\hline Tested range & 4 to 10 & 1 & $\begin{array}{c}4.15 \text { to } \\
6.55\end{array}$ & 1 to 3.30 & 75 to 100 & 1 to 3 & 1 to 2 \\
\hline $\begin{array}{c}\text { Suggested } \\
\text { range }\end{array}$ & 3 to 12 & 1 & $\begin{array}{c}3.15 \\
\text { to }\end{array}$ & 0.30 to $^{\dagger}$ & 75 to 100 & $\begin{array}{c}\text { Any } \\
\text { number }\end{array}$ & $\begin{array}{c}\text { Any } \\
\text { number }\end{array}$ \\
\hline
\end{tabular}

* Limited only by semi-prefabrication and transportation facilities.

Upper-bound depends mainly on $L$ through structural and constructional issues. Note: $1 \mathrm{~m}=3.279 \mathrm{ft} ; 1 \mathrm{~mm}=0.03937 \mathrm{in}$. 
Table 2-Tested vaults

\begin{tabular}{|c|c|c|c|c|c|c|c|}
\hline $\begin{array}{l}\text { Vault } \\
\text { name }\end{array}$ & $L \times H \times h \times b, \mathrm{~m}$ & $\begin{array}{c}\text { Support } \\
\text { conditions }\end{array}$ & $\begin{array}{c}\text { Top/bottom } \\
\text { reinforcement, } \\
\mathrm{mm}^{2} / \mathrm{m}\end{array}$ & $\begin{array}{c}\text { Top/bottom } \\
\text { steel yielding point, } \mathrm{MPa}\end{array}$ & $\begin{array}{l}\text { Top/bottom } \\
\text { mechanical } \\
\text { cover, mm }\end{array}$ & $\begin{array}{c}\text { Top/bottom } \\
\text { mortar strength, } \\
\mathrm{MPa} \\
\end{array}$ & $\begin{array}{l}\text { Loading } \\
\text { position }\end{array}$ \\
\hline $\mathrm{u} 1, \mathrm{u} 2$ & $4 \times 1 \times 0.075 \times 1$ & Hinged ends & $0 / 251.33$ & -1500 & $-/ 19$ & $21.00 / 13.00$ & $L / 4$ \\
\hline u3 & $4 \times 1 \times 0.075 \times 1$ & Hinged ends & $0 / 251.33$ & $-/ 500$ & $-/ 19$ & $56.32 / 56.32$ & $L / 4$ \\
\hline $\mathrm{u} 4$ & $4 \times 1 \times 0.075 \times 1$ & Hinged ends & $0 / 141.37$ & -1400 & $-/ 18$ & $53.46 / 53.46$ & $L / 4$ \\
\hline u5 & $4 \times 1 \times 0.075 \times 1$ & Hinged ends & $0 / 141.37$ & -1400 & $-/ 18$ & $38.57 / 28.26$ & $L / 4$ \\
\hline v1 & $4 \times 1 \times 0.075 \times 1$ & Hinged ends & $0 / 141.37$ & $-/ 3 \times 500+2 \times 400^{*}$ & $-/ 17$ & $2.92 / 4.35$ & $L / 2$ \\
\hline v2 & $4 \times 1 \times 0.075 \times 1$ & Hinged ends & $141.37 / 251.33$ & $400 / 500$ & $42 / 13$ & $2.09 / 3.34$ & $L / 2$ \\
\hline v3 & $4 \times 1 \times 0.075 \times 2$ & Hinged corners & $141.37 / 141.37$ & $400 / 8 \times 500+2 \times 400^{\dagger}$ & $42 / 13$ & $4.578 / 4.578$ & $L / 2$ \\
\hline v5 & $6 \times 1 \times 0.075 \times 1$ & Hinged ends & $141.37 / 141.37$ & $500 / 3 \times 500+2 \times 400^{*}$ & $42 / 15$ & $3.937 / 3.937$ & $L / 3$ \\
\hline v6 & $10 \times 3.30 \times 0.075 \times 1$ & Clamped ends & $251.33 / 141.37$ & $500 / 500$ & $57 / 18$ & $25.495 / 25.495$ & $L / 4$ \\
\hline v7 & $4 \times 1 \times 0.01 \times 1$ & Hinged ends & $141.37 / 251.33$ & $500 / 500$ & $67 / 13$ & $25.097 / 25.097$ & $L / 2$ \\
\hline v8 & $4 \times 1 \times 0.075 \times 1$ & Hinged ends & $141.37 / 251.33$ & $500 / 500$ & $22 / 16$ & $41.420 / 41.420$ & $L / 2$ \\
\hline v9 & $4 \times 1 \times 0.075 \times 1$ & Hinged ends & $141.37 / 251.33$ & $500 / 500$ & $22 / 16$ & $37.970 / 37.970$ & $L / 2$ \\
\hline v10 & $4 \times 1 \times 0.075 \times 1$ & $\begin{array}{c}\text { Hinged } \\
\text { sliding ends }\end{array}$ & $141.37 / 251.33$ & $500 / 500$ & $22 / 16$ & $36.580 / 36.580$ & $L / 2$ \\
\hline
\end{tabular}

"In three inner bars, $f_{y k}=500 \mathrm{MPa}$; in two outer ones, $f_{y k}=400 \mathrm{MPa}$

In one sheet, $f_{\mathrm{vk}}=500 \mathrm{MPa}$ in the three inner bars and $f_{\mathrm{yk}}=400 \mathrm{MPa}$ in the two outer ones; in the other sheet, $f_{\mathrm{yk}}=500 \mathrm{MPa}$ in all bars.

Note: $1 \mathrm{~m}=3.279 \mathrm{ft} ; 1 \mathrm{~mm}=0.03937$ in.; $1 \mathrm{MPa}=145 \mathrm{psi}$.

$h_{1}^{1}$

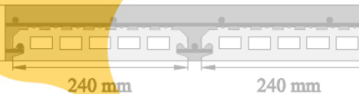

$240 \mathrm{~min}$

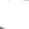

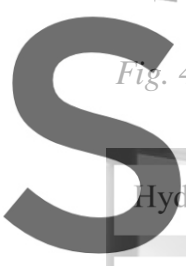

$240 \mathrm{~mm}$
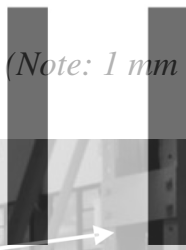

$240 \mathrm{~mm}$

Loading frame

Register for free at https//www.scipedia.com to

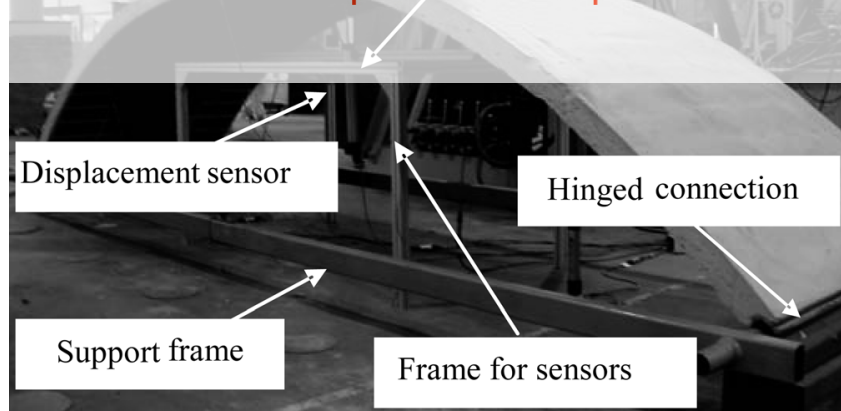

Fig. 5-Testing rig for Vault $v 1$.

modes do not involve the rupture of units; nevertheless, the brick strength was determined by carrying out uniaxial compression tests according to EN 772-1. ${ }^{6}$ The determined compressive strength ranged between 48.5 and $57 \mathrm{MPa}$ (79.75 and $87 \mathrm{ksi})$. For all of the vaults, the width of each strip was $l=1 \mathrm{~m}(3.279 \mathrm{ft})$.

Table 2 shows that some of the vaults are either alike (u1 and $\mathrm{u} 2$ ) or near-alike (v8 and v9); given the uncertainty inherent to the structural performance of the vaults, this duplicity allows for deriving sounder conclusions. Moreover, some of the vaults differ only in the values of one parameter to assess its individual influence (u4 and u5).
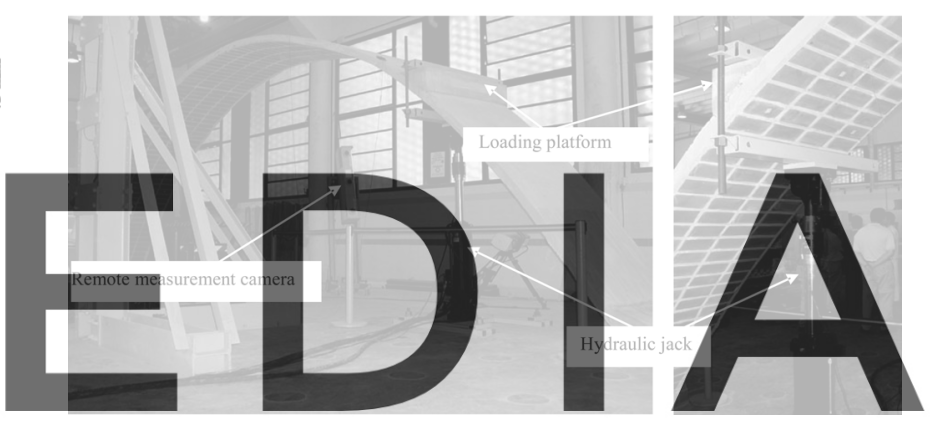

Fig. 6-Testing rig for Vault v6.

download the version without the watermark
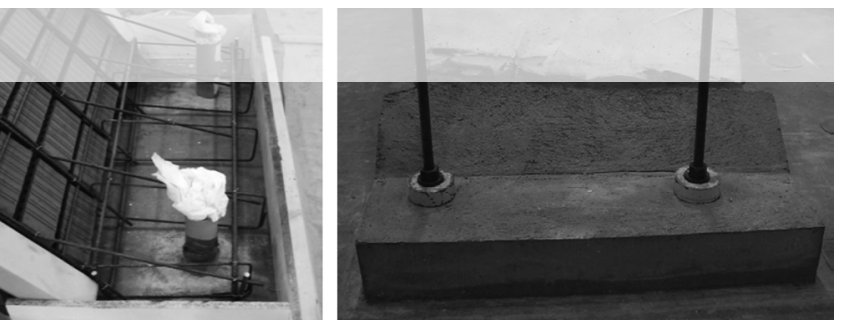

Fig. 7-End connections of Vault $v 6$.

All of the sheets were manufactured on the premises of the company leading the consortium of the ISO-BRICK project. Vaults $\mathrm{u} 1$ and $\mathrm{u} 2$ were built and tested at the Girona University laboratory whereas the remaining vaults were built and tested at the Laboratory of Construction Technology of the Technical University of Catalonia.

Figures 5 and 6 show global views of the testing assemblies for Vaults v1 and v6, respectively. Figure 7 displays the support conditions of Vault $v 6$. The clamping was produced by fixing the end part of the vault to the floor with two prestressed bolts (Fig. 7, right). The top and bottom reinforcements were anchored into this end part (Fig. 7, left).

The experiments can be classified in four groups, depending on the type of loading: 


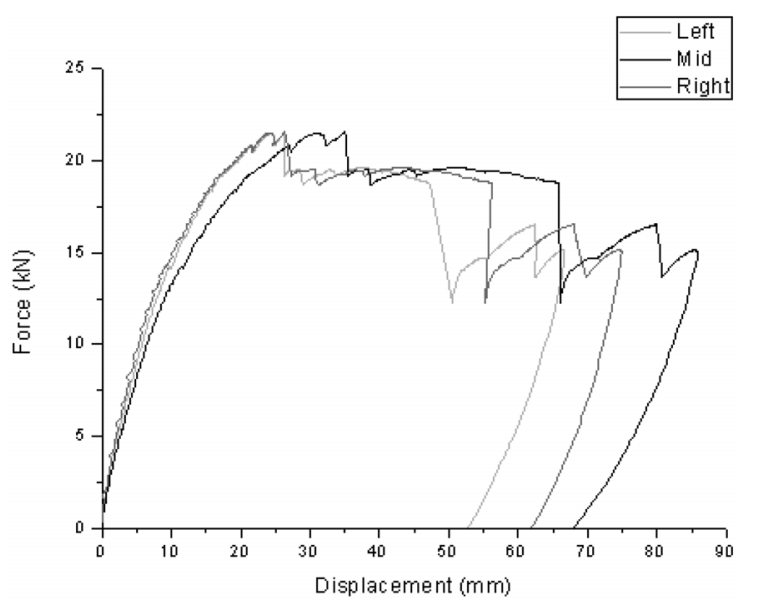

Fig. 8-Load-deflection plots for Vault v3. (Note: $1 \mathrm{~mm}=$ 0.03937 in.; $1 \mathrm{kN}=0.2248$ kip.)
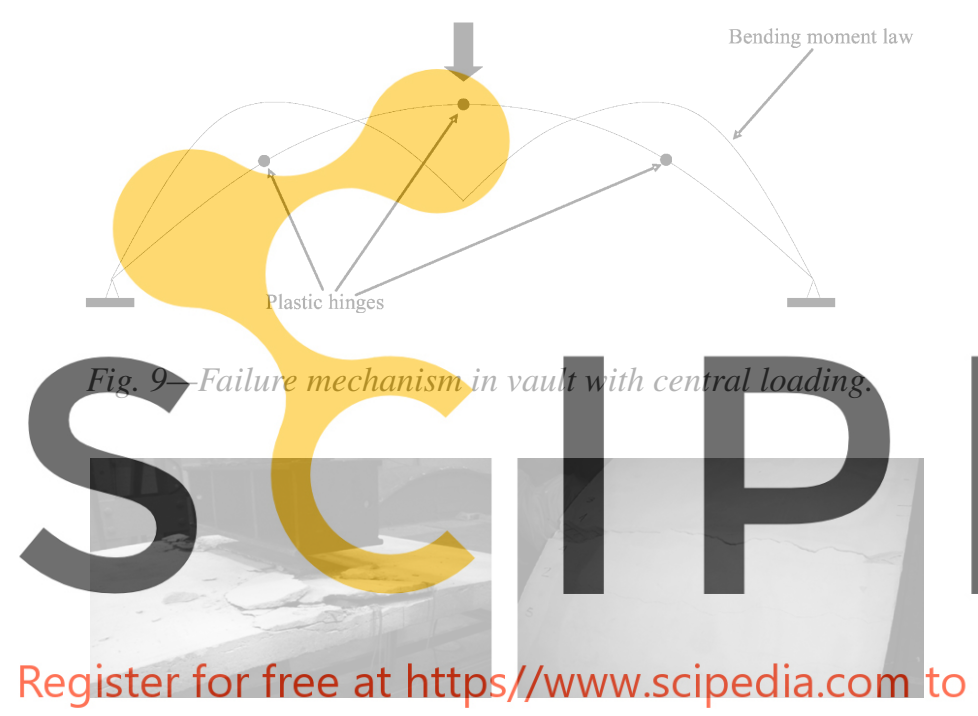

Fig. 10=Plastic hinges in Vault v1.

- Line instantaneous loading-Vaults u1, u2, u3, u4, u5, v1, v2, v5, v6, v8, v9, and v10. The load was applied through a transversal rigid steel beam pushed or pulled vertically by a hydraulic jack (refer to Fig. 5 and 6). When the load was eccentric (as in Vaults u1, u2, u3, u4, u5, v5, and v6; refer to Table 2), loading platforms were used to provide an even horizontal loading surface (refer to Fig. 5). This transversal beam reached most of the vault width because the supports also sustain the whole width of the vault (refer to Table 2), no relevant transversal bending was expected. The main objective of these tests was to investigate the ductility and the loading capacity.

- Point instantaneous loading-Vault v3. The load was applied by a short transversal rigid steel beam pushed vertically by a hydraulic jack. This beam reaches only a minor part of the vault width; because the supports sustain only the corners of the vault (refer to Table 2), transversal bending might be relevant. The main objective of this test was to investigate the importance of biaxial bending.

- Sustained loading - Vault v7. The load was applied by cement bags. The main objective of this test was to investigate the creep behavior.
- Support displacement plus line instantaneous loading Vault v10. As shown in Table 2, Vaults v8, v9, and v10 were designed to be alike; however, Vaults v8 and v9 did not experience any support displacement, whereas Vault v10 experienced a longitudinal horizontal displacement of $45 \mathrm{~mm}$ (1.77 in.) of one of the supports previously released. The main objective of this test was to investigate the influence on the loading capacity of the lateral flexibility of the supporting members.

The loads were applied at a speed of $10 \mathrm{~mm} /$ minute (0.3937 in./minute for Vaults $\mathrm{u} 1$ and $\mathrm{u} 2,5 \mathrm{~mm} /$ minute (0.1969 in./minute) for Vaults u 3 to u 5 and v1 to v6, and $2.5 \mathrm{~mm} /$ minute $(0.0984 \mathrm{in} . /$ minute $)$ for Vaults $\mathrm{v} 8$ to $\mathrm{v} 10$. These velocities were increased in the descending branches.

The measured magnitudes were the applied forces, the horizontal and vertical displacements of relevant points in the vaults, and the strains of some reinforcement bars and of some steel members of the support frames. As shown in Fig. 6, remote sensing was employed for measuring the displacements of Vault v6; in the other vaults, the displacements were registered by LVDT sensors. The stroke of such displacement transducers was $300 \mathrm{~mm}$ (11.81 in.) and the accuracy error was less than $0.005 \%$; smaller sensors were used for locations where smaller displacements were expected. The hydraulic jack included a load cell and an LVDT to register the loading force and the piston displacement, respectively. The load cell capacity was $500 \mathrm{kN}$ (11.24 lbf) and the maximum accuracy error was $0.5 \%$.

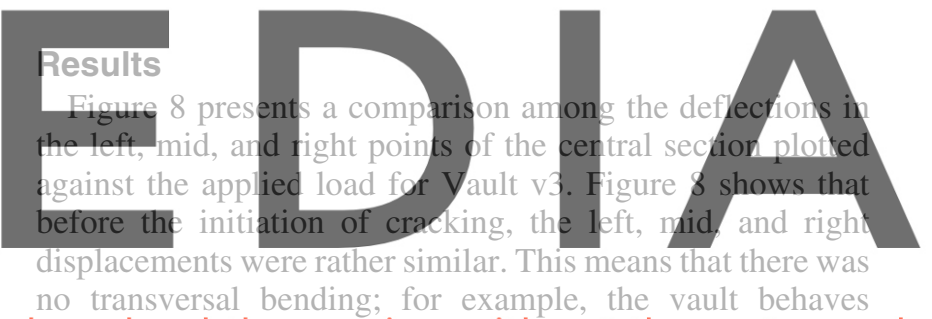

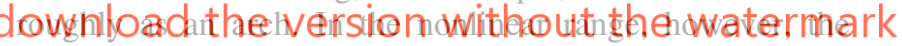
deflection of the loaded point (mid) was larger, showing a certain transversal bending.

As shown in Fig. 8, the vaults exhibited a rather uniaxial behavior, with the longitudinal bending being largely predominant over the transversal one. Therefore, because the vaults are statically redundant, collapse was attained after the formation of the required number of plastic hinges. Such hinges extended along the full width of the vaults. Figure 9 shows the observed failure mechanisms of a simplysupported, centrically-loaded vault (Vaults v1, v2, v3, v8, v9, and v10) (refer to Table 2).

To highlight the collapse mechanism, Fig. 9 displays the bending moment law. Such a mechanism was a damage pattern composed of three plastic hinges. In the central hinge, the moments were positive and, hence, the tensions were in the intrados whereas this trend was inverted in the other two hinges corresponding to negative moments. The central hinge appeared for load values lower than those of the eccentric ones. For eccentrically loaded vaults (u1, u2, u3, u4, u5, v5, and v6, refer to Table 2) similar failure mechanisms were observed. The distribution of plastic hinges in Vault v1 is shown in Fig. 10. The left image in Fig. 10 shows spalling (compressed side) whereas the right image shows cracking (tensioned side). Figure 11 displays the vertical displacement of the mid-section versus the applied force for Vaults v1 and v2. 
Table 3-Comparison between numerical and experimental collapse loads, $\mathbf{k N}$

\begin{tabular}{|c|c|c|c|c|c|c|c|c|c|c|c|c|c|}
\hline Vault & $\mathrm{u} 1$ & u2 & u3 & $\mathrm{u} 4$ & u5 & $\mathrm{v} 1$ & v2 & v3 & v5 & v6 & v8 & v9 & v10 \\
\hline Test results & 19.50 & 21.00 & 26.50 & 15.20 & 14.20 & 16.35 & 14.22 & 21.52 & 8.52 & 14.23 & 35.45 & 45.15 & 36.29 \\
\hline PRO-SHELL & - & - & $\begin{array}{c}27.5 \\
26.0^{*}\end{array}$ & - & - & 16.50 & 16.30 & 24.00 & 7.70 & $\begin{array}{c}12.70^{\dagger} \\
20.70^{\ddagger} \\
18.90^{*}\end{array}$ & 45.40 & 45.40 & - \\
\hline DBS-ROOF & 20 & 20 & 21.4 & 10.4 & 10.3 & 16.20 & 17.30 & 22.00 & 9.00 & $\begin{array}{l}10.60^{\dagger} \\
15.80^{\ddagger}\end{array}$ & 43.50 & 43.50 & - \\
\hline
\end{tabular}

*Second order analysis.

${ }^{\dagger}$ Hinged ends.

$\doteqdot$ Clamped ends.

Note: $1 \mathrm{kN}=224.82 \mathrm{lbf}$.

Table 4-Main test results

\begin{tabular}{c|c|c|c|c|c|c|c|c|c|c|c|c|c}
\hline Vault & $\mathrm{u} 1$ & $\mathrm{u} 2$ & $\mathrm{u} 3$ & $\mathrm{u} 4$ & $\mathrm{u} 5$ & $\mathrm{v} 1$ & $\mathrm{v} 2$ & $\mathrm{v} 3$ & $\mathrm{v} 5$ & $\mathrm{v} 6$ & $\mathrm{v} 8$ & $\mathrm{v} 9$ & $\mathrm{v} 10$ \\
\hline Collapse load, $\mathrm{kN}$ & 19.50 & 21.00 & 26.50 & 15.20 & 14.20 & 16.35 & 14.22 & 21.52 & 8.52 & 14.23 & $35.45^{*}$ & 45.15 & 36.29 \\
\hline Deflection at peak, $\mathrm{mm}$ & 26 & 27 & 44 & 42 & 37 & 29 & 25 & 35 & 33 & 111 & 46 & 61 & 74 \\
\hline Tangential stiffness, $\mathrm{kN} / \mathrm{mm}$ & 1.94 & 2.71 & 3.42 & 3.16 & 2.94 & 2.43 & 1.59 & 1.92 & 0.474 & 0.137 & 1.50 & 2.17 & 1.55 \\
\hline Secant stiffness, $\mathrm{kN} / \mathrm{mm}$ & 1.37 & 2.37 & 1.54 & 1.17 & 1.03 & 1.25 & 0.93 & 1.18 & 0.452 & 0.137 & 1.21 & 1.45 & 1.21 \\
\hline
\end{tabular}

*This test was interrupted before reaching collapse.

Note: $1 \mathrm{kN}=224.82 \mathrm{lbf} ; 1 \mathrm{~mm}=0.03937 \mathrm{in}$.

Figure 11 shows that Vaults v1 and v2 exhibited a regular and ductile behavior, with an initial linear elastic loading branch, a progressive and smooth degradation after the onset of cracking, and an unloading branch with a certain recovery majority of tested vaults. As can be seen in Table 2, the most ralevant differences between absence of upper reinforcement in Vault v1, the higher andount of lower reinforcement in Vault y2, and the higher mortar strength in Vault $\mathrm{v} 1$ (although such strength was still extremely low). The comparison between the two plots in Fig. 11 showed that Vault v1 was slightly stiffer in the elastic

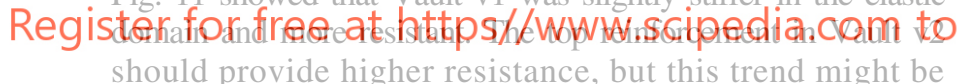
compensated by the higher mortar strength; a deeper discussion is included next in this section. It is remarkable that the higher resistance of Vault v1 was satisfactorily predicted by numerical simulation, as shown further in Table 3 . The abrupt decrease in the descending branch of Vault v1 was apparently due to the sudden onset of the eccentric plastic hinges (refer to Fig. 9) because of the lack of top reinforcement.

For each of the tested vaults, Table 4 shows the collapse loads, the deflections at the loaded section, and the tangent (initial) and secant stiffness obtained the slopes of the load-deflection plots. The tangent and the secant stiffness correspond to $5 \mathrm{kN}(1124 \mathrm{lbf})$ and to $60 \%$ of each collapse load, respectively.

Results from Table 4 show that the strength and the stiffness of the vaults were largely sufficient for the common design loads for light roofs (EN-1991-2-17). Regarding the initial and tangential stiffness, high scattering was observed, with little correlation with the most relevant structural parameters. Comparison with theoretical values from linear elastic analyses (accounting for the joint behavior of bricks, mortar, and steel) shows that both parameters were overestimated by a factor ranging from 1.69 to near 10. Therefore, this type of analysis is not useful for structural design.

A deeper insight into Table 4, taking into account the characteristics of the vaults indicated in Table 2, allows some

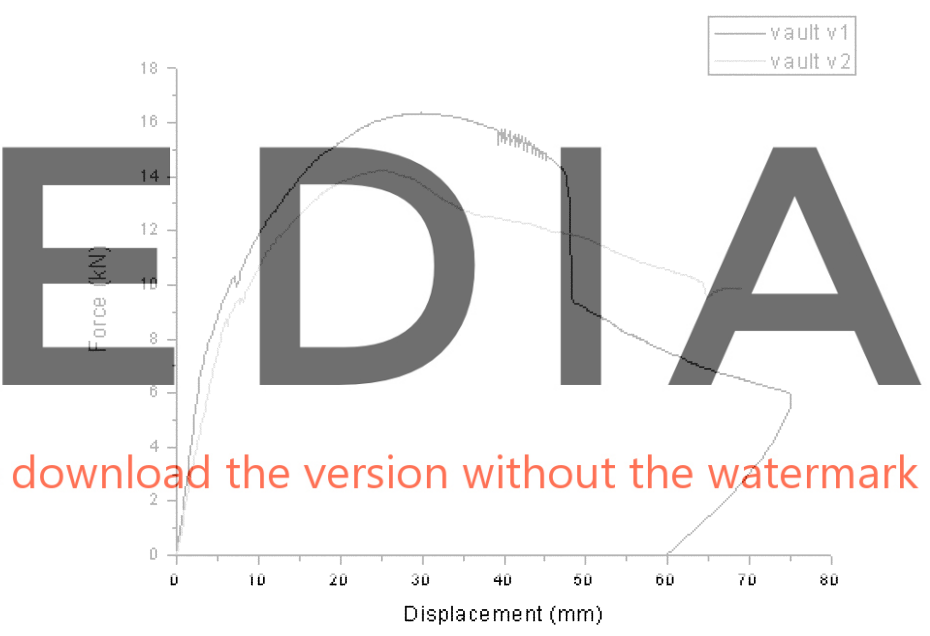

Fig. 11-Load-deflection plots for Vaults v1 and v2. (Note: $1 \mathrm{~mm}=0.03937$ in.; $1 \mathrm{kN}=0.2248$ kip.)

general conclusions on the influence of the most relevant parameters and features of the vaults.

- Mortar strength-In general, a small influence of the mortar strength on the flexural resistance of the vaults should be expected. A comparison between Vaults u1 and $\mathrm{u} 2$ on one hand and Vault $\mathrm{u} 3$ on the other hand shows that a higher mortar strength yielded significantly higher collapse loads and initial stiffness compared to poor mortar. For vaults built with poor mortar (Vaults v1 and $\mathrm{v} 2$ ), and for positive bending moments (compression in the extrados), the depth of the compressed zone had a strong influence on the distance between compression and tension resultants, given the small effective depth of the vaults. The results of Vaults v1 and v2 show that, even using unusually poor mortar, the vault strength and the displacement ductility were sufficient (refer to Fig. 11). The comparison of Vaults $\mathrm{u} 4$ and $\mathrm{u} 5$ shows that the effect of the mortar strength was significantly less intense for vaults built with higher strength mortar. 


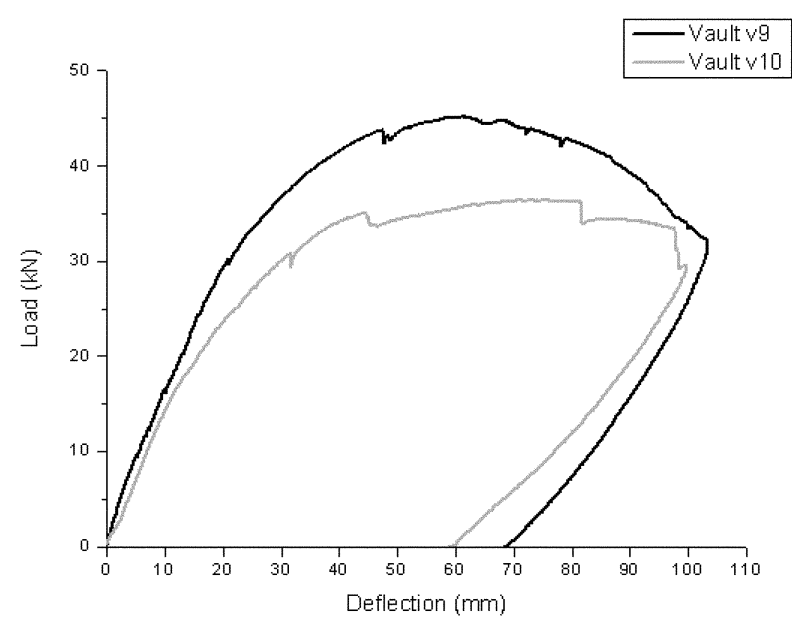

Fig. 12-Load-deflection plots for Vaults $v 9$ and v10. (Note: $1 \mathrm{~mm}=0.03937$ in.; $1 \mathrm{kN}=0.2248 \mathrm{kip}$.)
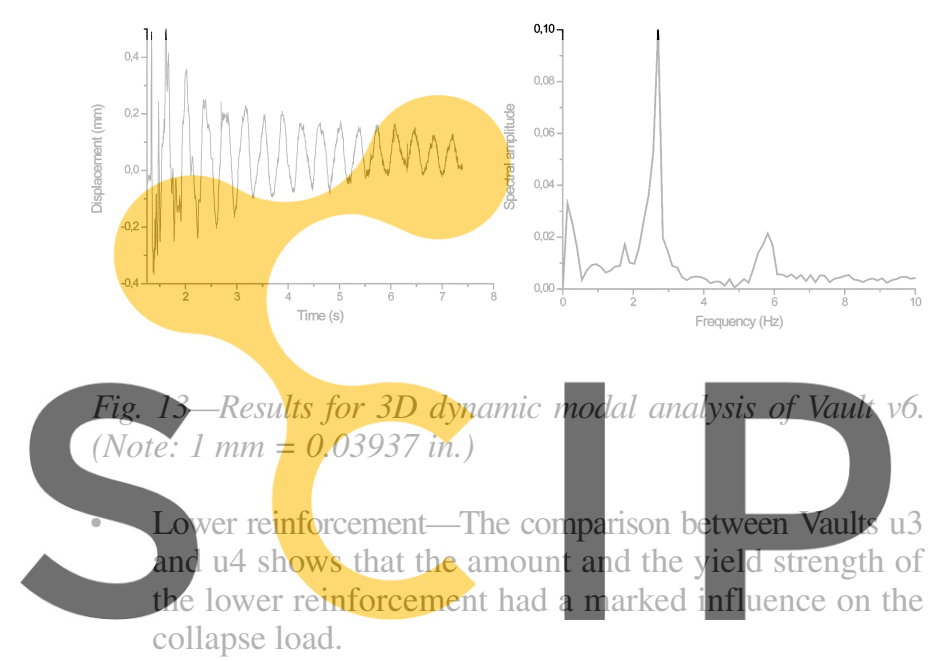

Regi Top reinforcement-Figure 9 suggests that the influence of

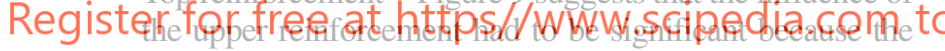
collapse mechanism involved the formation of hinges corresponding to negative bending moments. The comparison between Vaults $\mathrm{u} 3$ and $\mathrm{v} 9$ (even considering the influence of the loading position) shows that the existence of upper reinforcement had generated an important increase in the ultimate load despite the mortar strength being higher in Vault u3. Conversely, the comparison between Vaults v1 and v2 (refer to Fig. 11) shows that, for poor mortar, the influence of the compression strength on the ultimate capacity was very significant.

- Loading position-As should be expected in structures developing ultimate mechanisms similar to those of unreinforced masonry and concrete arches, the arches developed larger capacity for loads applied at midspan than for loads applied eccentrically at $1 / 4$ or $1 / 3$ of the span. This trend was clearly seen by comparing the response of vaults loaded at different points and, particularly, by comparing Vault u3 with Vaults v8 and v9 and Vaults u1 to u5 with Vaults v1, v2, v3, v8, and v9.

- Span length and rise-The comparison between Vaults v2 and v5 shows that, as expected, the collapse load of the vault with a larger span length was significantly smaller (after discarding the influence of the other aspects). Conversely, the strength of Vault v6 was larger than that of Vault v5 in spite of its longer span; this can be due to the positive effect of its higher rise/span-length ratio.
- Vault width-The comparison between Vaults v2 and v3 shows that the strength-width ratio was higher for the narrower vault; similar conclusions were derived for the initial stiffness. This seems to indicate that, although the longitudinal bending largely predominates over the transversal one, the contribution of the outer unloaded longitudinal bands was smaller than that of the central loaded one. The existence of a certain transversal bending in Vault v3 was recognizable in Fig. 8; because this effect was small, the difference in support conditions did not significantly affect the resistance.

- Sliding supports-Vaults v8, v9, and v10 are designed alike to assess the influence in the loading capacity of initial horizontal relative displacements between the two supports. The initial planning was to select three slide values: null for Vault v8, small for Vault v9, and larger for Vault v10. The test of Vault v8, however, was interrupted before reaching the final failure (because of a breakdown of the jack) and, hence, it was decided to test Vault v9 under vertical load only, whereas Vault v10 underwent an initial displacement; its value $(45 \mathrm{~mm}$ [1.77 in.]) was determined by numerical simulation looking for a relevant reduction in the collapse load. The comparison between Vaults v10 and v9 evidences that the horizontal slide significantly impaired the loading capacity and the initial stiffness. Figure 12 displays the vertical displacements of the midsection plotted against the applied loads.

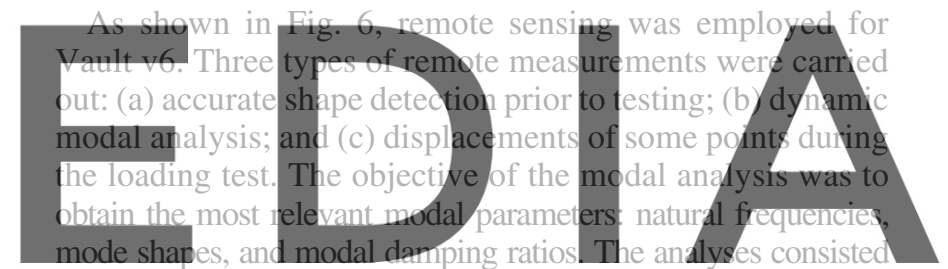

of applying pulse loads and measuring the free response. Threedimensional (3D) and six-dimensional (6D) analyses were

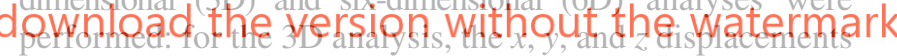
of the sensor points were measured, whereas for the 6D analysis, the roll, pitch, and yaw angles were also registered. Three-dimensional analyses allowed the detection of the longitudinal bending modes and 6D analyses allowed detection of the torsion and the lateral bending modes. For the 3D analyses, the input pulse was applied in the midline of the vault, whereas in the $6 \mathrm{D}$ analyses it was eccentric. Figure 13 shows some results for the 3D analysis; Fig. 13(a) displays the time history of a vertical displacement and Fig. 13(b) exhibits its Fourier transform.

Figure 13(a) shows that the damping can be roughly described by a viscous model; the equivalent damping factor was approximately equal to $4.5 \% .{ }^{8,9}$ Figure 13 (b) shows that the first two natural frequencies were $f_{1}=2.7 \mathrm{~Hz}$ and $f_{2}=5.8 \mathrm{~Hz}$. The frequency of the first mode can be compared to the one of an equivalent single-degree-of-freedom system given by

$$
f_{1}=\sqrt{k / m} / 2 \pi
$$

the tangent stiffness $k$ was taken from the experimental result in Table 4 and the equivalent mass $m$ was computed from the well-known ${ }^{8,9}$ expression

$$
m=\int_{0}^{S} m_{0} \psi^{2}(s) d s
$$




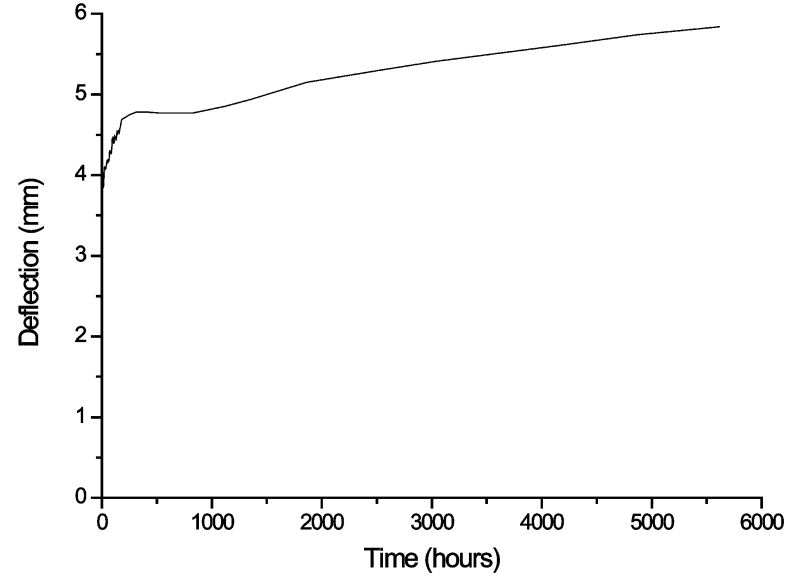

Fig. 14-Time-deflection plots for Vault v7. (Note: $1 \mathrm{~mm}=$ 0.03937 in.)

where $m_{0}$ is the mass per unit length, $s$ is the arc-length of the vault, and $\psi(s)$ is the modal shape. By assuming a shape similar to the deformation of the vault for an eccentric concentrated load, the obtained result was $f_{1}=2.44 \mathrm{~Hz}$; the agreement with the experimental result was satisfactory. The other peaks in Fig. 13(b) would correspond to noise.

Vault v7 was subjected to a sustained load of $6 \mathrm{kN}$ (1348.92 lbf) to characterize the instantaneous and timedependent behavior. Figure 14 presents the time history of

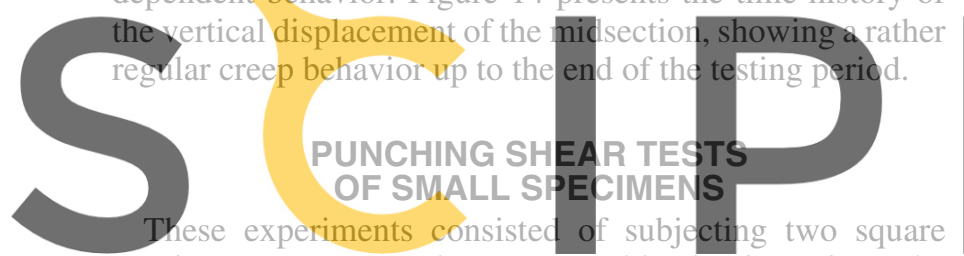
specimens to a centered concentrated load to investigate the punching shear strength. The specimens were flat, as their

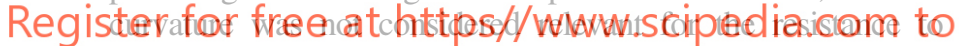
punching shear because it was a rather localized phenomenon. The two specimens were $80 \times 80 \mathrm{~cm}(31.50 \times 31.50 \mathrm{in}$.) wide and $7.5 \mathrm{~cm}$ (2.95 in.) deep and differed only in their upper reinforcement: the steel welded mesh and expanded metal sheet. The test consisted of lying the simply supported specimens flat along their borders and applying the punching load distributed on a square $10 \times 10 \mathrm{~cm}(3.94 \times 3.94$ in.) area.

Figure 15 displays the plots of the applied load versus the loading jack displacement for both specimens. Figure 15 shows that the specimens possessed a sufficient punching shear strength as the maximum values $(11.9 \mathrm{kN}$ [2675 lbf] for the expanded metal sheet and $16.5 \mathrm{kN}$ [3710 lbf] for the steel mesh) were significantly larger than those prescribed by norms (for example, $1.5 \mathrm{kN}$ [337 lbf] according to European regulations ${ }^{6}$ ) and those expected for normal working conditions. In the specimen with steel welded mesh reinforcement, the separation among consecutive bars was $25 \%$ larger than the size of the loading area and such load was applied between two adjoining ribs; in spite of that, the resistance was higher for the specimen with the steel mesh and its behavior was more ductile.

\section{NUMERICAL MODELS}

The spreading and improvement of any construction technology requires reliable numerical approaches to simulate and predict the structural behavior. Two types of algorithms have

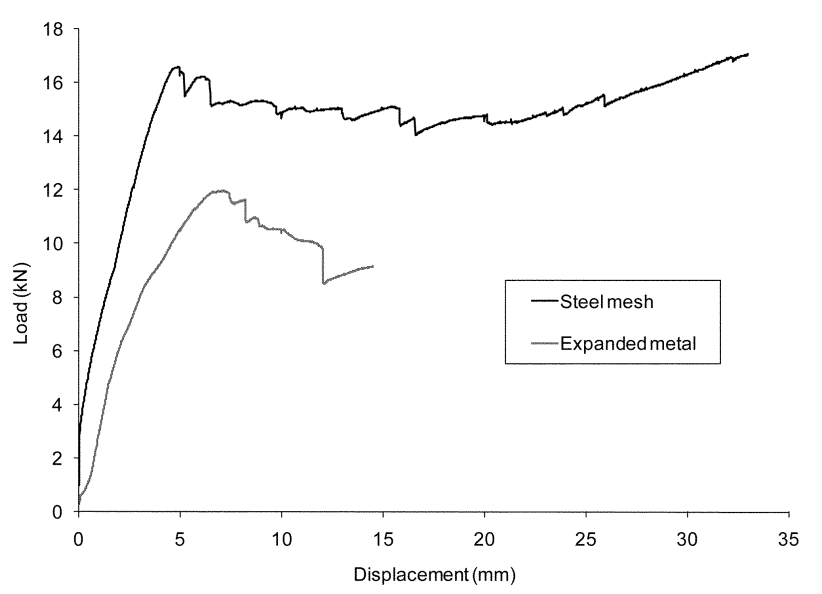

Fig. 15-Load-displacement plots for punching shear tests. (Note: $1 \mathrm{~mm}=0.03937$ in.; $1 \mathrm{kN}=0.2248$ kip.)

been developed: 1) an accurate nonlinear finite element model $^{10}$ (termed PRO-SHELL) able to account for all of the relevant structural issues; and 2) a simpler algorithm ${ }^{11}$ (termed DBS-ROOF) capable to cope only with the essential aspects. Because the first model is inherently complex and computationally expensive, it was not envisaged as a practical design tool, but as an instrument either to derive general conclusions or to deal with complex or daring solutions. Conversely, the second model was mainly

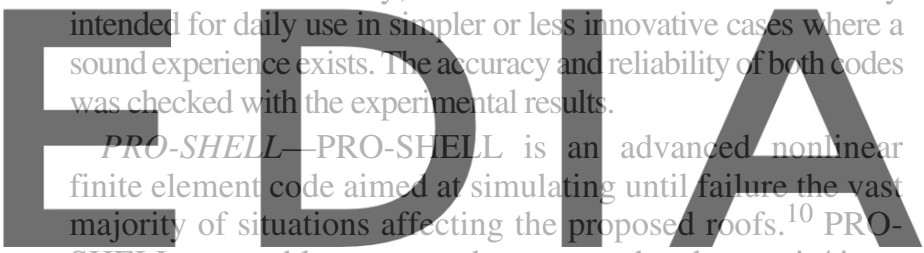
SHELL was able to reproduce second-order static/timedependent/dynamic shell behavior, accounting for large d ouvplaadethecrearsion wistheu to thewmate nimark Dynamic capabilities included both linear modal analysis and nonlinear transient response using the Newmark method. The possibility of considering large displacements was relevant given the big flexibility of the vaults, mostly near failure. Direct and indirect actions were simulated; indirect actions involved either uniform or gradient effects. Both brittle (brick units and mortar) and plastic (steel) materials were considered. Following a micromodeling approach, each material (steel, brick, and mortar) was represented independently, whereas no special materials were used for interfaces. Brick units and mortar were described by a multiaxial isotropic damage model. ${ }^{10}$ The required parameters for brick units and mortar were the deformation moduli, the tensile and compressive strength, and Poisson's ratio; their values were derived from the tests. Steel was described by a uniaxial bilinear plastic model without strain hardening; the yielding point and the deformation modulus were obtained from testing and the maximum longitudinal strain was $20 \%$. The vaults were modeled by 3D serendipit parallelepiped elements with 20 nodes and three degrees of freedom (DOF) per node corresponding to $\mathrm{u}, \mathrm{v}$, and $\mathrm{w}$ displacements. The contribution of the expanded metal sheet (refer to Fig. 2) to the stiffness and strength is neglected; this assumption was confirmed by experiments described by Oliveira et al. ${ }^{12}$ The pre- and postprocessing user interfaces are eased through GiD code. ${ }^{13}$ 


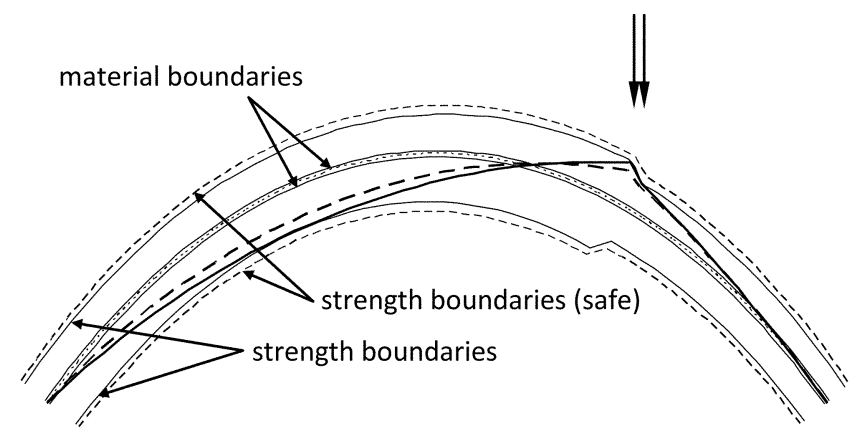

Fig. 16-Thrust lines derived from DBS-ROOF code.
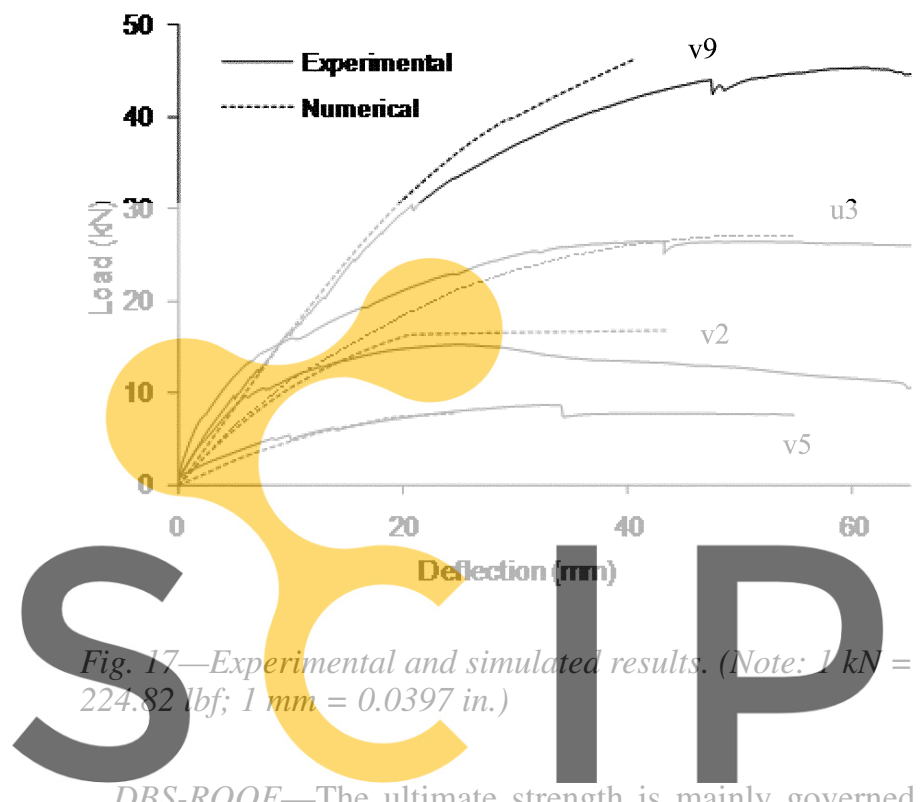

$D B S-R O O F$ - The ultimate strength is mainly governed by the ductile formation of transversal hinges as confirmed

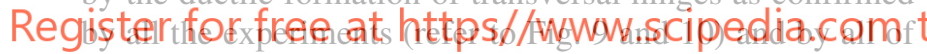
the numerical simulations using PRO-SHELL. This fact suggests that a simple unidirectional plastic limit analysis may yield quite accurate estimations of the collapse loads and failure modes. This idea motivated the creation of DBSROOF code ${ }^{11}$ consisting of a graphically oriented method to apply simple static limit analysis on reinforced arches. The main innovation consists of representing the reinforcement in terms of an equivalent depth enlargement defined by new top and bottom resisting boundaries. The method is similar to limit analysis for masonry arches, well known after Jacques Heyman's work, ${ }^{14}$ and is based on applying the limit theorems of plasticity. DBS-ROOF includes an extension to reinforced masonry arches and vaults based on substituting the real boundaries of the arch by a new set of boundaries expanded to account for the contribution of the steel reinforcement. This generalization that can be done is an exact way thanks to the plastic nature of the material (steel) used to reinforce the structure. Figure 16 displays an example of thrust lines obtained by applying the safe (or lower-bound) and uniqueness theorems, both lying inside the two strength boundaries determined for the existing reinforcement. The collapse mechanism determined by the application of the uniqueness theorem is characterized by the appearance of two hinges located in the points where the thrust line becomes tangent to the resisting boundaries.

\section{COMPARISON BETWEEN NUMERICAL AND EXPERIMENTAL RESULTS}

The tests were simulated with PRO-SHELL and DBS-ROOF to assess their accuracy and reliability. Table 3 presents the numerical and experimental collapse loads. The values in Table 3 demonstrate a sufficient degree of accuracy, given the complexity of the analyzed situations and the possible scattering of the geometrical and mechanical parameters. Importantly, most of the predictions by PRO-SHELL were on the safe side.

In Vault v6, the fact that the vault failed without visible damage in the supports suggests that they did not actually behave as a perfect clamped connection, but allowed a certain rotation (refer to Fig. 7). Therefore, two possibilities are considered in the simulation: hinged and clamped ends. The actual situation seems to be rather intermediate, both according to PRO-SHELL and DBS-ROOF. Moreover, according to a nonlinear geometric analysis performed with PRO-SHELL, the capacity obtained when the second order effects were taken into consideration was slightly smaller than those resulting from a first order effect and matched the experimental value better

Regarding Vault v10, the observed strength reduction compared to Vault v9 (approximately 20\%) due to the support opening (45 mm [1.77 in.]) could not be reproduced by PRO-SHELL, which predicted a dramatic decrease for openings larger than $40 \mathrm{~mm}$ [1.57 in.]. This might be due to the difficulty of simulating the ultimate behavior by continuum mechanics because of the possible discrete opening of masonry joints and the sliding of the reinforcement.

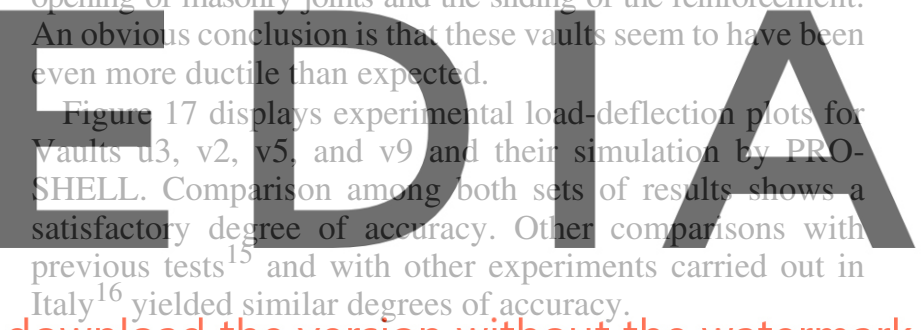
Italy yielded similar degrees of accuracy

\section{download the version without the watermark} SUMMARY AND CONCLUSIONS

This work presents experimental research carried out on 14 reinforced brick masonry full-scale thin vaults and on two small plate specimens. The tests on the vaults consisted mainly of the application of gradually increasing concentrated loading until failure. Additionally, one vault was subjected to sustained loading. The plate specimens underwent punching shear tests.

The main conclusions arising from the research are as follows:

- A satisfactory loading and punching shear capacity was obtained in all the cases. The resulting ultimate loading capacity was always higher than required by design codes for expectable architectural applications such as light roofs.

- The structural behavior showed significant ductility, meaning that imposed support displacements caused only a moderate loss of loading capacity.

- In general, the reinforcement had a higher influence in the loading capacity than the mortar strength. If unusually poor mortar was used, such a trend was inverted; in such a case the vault strength was still sufficient, yet the use of more resistant mortar significantly increases the capacity.

- The initial and tangential stiffness were grossly overestimated by theoretical values from linear elastic analyses. Consequently, such analyses were not useful for structural design. 
- The structural behavior was satisfactorily simulated numerically by means of nonlinear approaches. An advanced finite element model afforded acceptable predictions of response along the entire loading process. A more simplified model, based on limit analysis, also showed the ability to predict the ultimate load and the failure mechanism.

These conclusions contributed to the validation of the structural behavior of the proposed vaults and the possibility of simulating their response numerically.

\section{ACKNOWLEDGMENTS}

This work has received financial support from the Catalonian Government (CIDEM, "CERARMAT" IT Technological Innovation Project 605) the Spanish Government (Ministry of Industry and Energy, "PRECERAM" ATYCA Project M172/1999), and the European Commission ("ISOBRICK" CRAFT Cooperative Research Project G5ST-CT-2001-50095). All of these supports are gratefully acknowledged.

\section{REFERENCES}

1. Huerta, S., "The Vaults of Guastavino in America," Spanish Ministry of Public Works, Instituto Juan de Herrera, 2001. (in Spanish)

2. Dieste, E., "The Brick Masonry Structure," Universidad de Los Andes, Colombia, 1987 (in Spanish)

3. Daguerre, M., Eladio Dieste 1917-2000, M. Electa, ed., 2003.

4. ISO-BRICK, "Industrial Solutions for Construction of Reinforced Brick Masonry Shell Roofs," Craft Research Project, Deliverable \#37, report about the Proposed Technologies (nonconfidential), European Commission 2004

5. EN 1015-11:1999, "Methods of Test for Mortar for Masonry: Determination of Flexural and Compressive Strength of Hardened Mortar,'
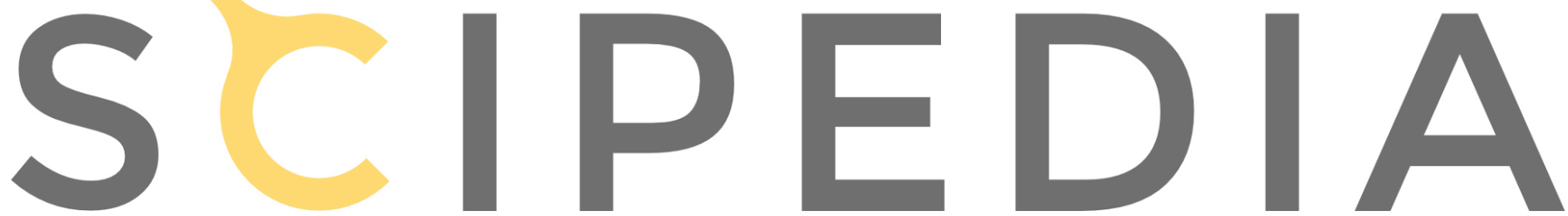

6. EN 772-1:2000, "Methods of Test for Masonry Units. Part 1: Determination of Compressive Strength," European Committee for Standardization, CEN/ TC 125,2001

7. EN 1991-2-1, "Basis of Design and Actions on Structures: Actions on Structures, Densities, Self-Weight, and Imposed Loads," European Committee for Standardization CEN, 1996.

8. Clough, R. W., and Penzien, J., Dynamics of Structures, McGraw-Hill, 1992.

9. Chopra, A. K., Dynamics of Structures, Prentice-Hall, 1995.

10. Hanganu, A. D.; Oñate, E.; and Barbat, A. H., "A Finite Element Methodology for Local/Global Damage Evaluation in Civil Engineering Structures," Computers \& Structures, V. 80, 2002, pp. 1667-1687.

11. Roca, P.; López-Almansa, F.; Miquel, J.; and Hanganu, A., "Limit Analysis of Reinforced Masonry Vaults," Engineering Structures, V. 29, No. 3, 2007, pp. 431-439.

12. Oliveira, J. T.; Barros, J. A. O.; Lourenço, P. J. B.; and Pinho, A. M., "Uniaxial Testing of Expanded Metal Sheet," Relatório Técnico 02/DEC/E-12, Departamento de Engenharia Civil, Universidade do Minho, Sept. 2002.

13. CIMNE, "GiD Program. The Personal Pre-Post Processor," The Universal Adaptive and User-Friendly Pre- and Post-Processing System for Computer Analysis in Science and Engineering, CIMNE, Barcelona, Spain. 2009. http://www.gidhome.com.

14. Heyman, J., The Masonry Arch, Chichester: Ellis Horwood, 1982

15. Sarrablo, V., "Contribution to the Feasibility of Reinforced Masonry Shell Roofs through Semi-Prefabricated Solutions. Proposal for Short Span Shells," PhD thesis, Architecture Structures Department, Technical University of Catalonia, Catalonia, Spain, 2002. (in Spanish)

16. da Porto, F.; Casarin, F.; Garbin, E.; Grendene, M.; Modena, C.; and Valluzzi, M. R., "Design Assisted by Testing of Semi-Prefabricated Reinforced Brick Masonry Vaults," 10th Canadian Masonry Symposium, Banff, AB, Canada, 2005.

\section{Register for free at https//www.scipedia.com to download the version without the watermark}

